\section{The influence of parenting style towards cooperative levels in children aged 3-5 years during dental treatment}

\author{
Andi SH. Yusuf ${ }^{1}, 2^{*}$, Nurhaedah Galib
}

\begin{abstract}
Objective: Children's behavior management problems are considered to be the most frequent problems that occur in pediatric dentistry. One of the factors that affect response behavior of children towards dental treatment is parenting style. The purpose of this study was to evaluate the influence of parenting style towards cooperative levels in children aged 3-5 years during dental treatment.

Material and Methods: The study was an observational analytical research with cross-sectional research design. To obtain data in the field, the study was conducted by distributing Parenting Style and Dimension Questionnaire (PSDQ) and frankl behavior rating scale to
\end{abstract}

130 respondents who are currently undergoing dental treatment in Dental Hospital Hasanuddin University.

Results: Results showed that there are simultaneous effects of independent variables on the dependent variable with a significance $<a(0.05)$, whereas the partial variables that have the most influence on patient cooperation is authoritarian with exponential $B$ value of 8.370 . Conclusion: There is a significant amount of influence of parenting style on the level of cooperation in children aged 3-5 years during dental treatment. Parents with authoritative parenting style would have made children cooperative 8 times higher compared with other parents following a different less rigid parenting style.
${ }^{1}$ Department of Pediatric, Faculty of Dentistry, Hasanuddin University, Makassar, Indonesia

2Department of General Dentist, Dentamedika Care Center, Makassar, Inonesia
*Corresponding to: Andi SH. Yusuf, Department of Pediatric, Faculty of Dentistry, Hasanuddin University, Makassar, Indonesia

hajrah.yusuf@gmail.com

Received: 29 August 2017

Revised: 10 ctober 2017

Accepted: 16 October 2017

Available online: 1 December 2017

Keywords: Child, Cooperative level, Dental treatment, Parenting style.

Cite this Article: Yusuf ASH, Galib N. 2017. The influence of parenting style towards cooperative levels in children aged 3-5 years during dental treatment. Journal of Dentomaxillofacial Science 2(3): 164-167. D0I: 10.15562/jdmfs.v2i3.609

\section{Introduction}

Nowadays, children's behavior management problems are considered to be the most frequent problems that occur in pediatric dentistry. ${ }^{1}$ Dental fear and behavior are likely to reflect characteristics, which are broadly divided into personal characteristics, environmental factors, or situational factors as it may reflect the general predisposition towards children's anxiety (trait-anxiety). Among all factors, it has been well-documented that parental dental fear strongly correlates with dental fear in their children. ${ }^{1,2}$

Children's development could be best understood within the framework of interaction between the infant and the primary caregiver. If there were problems in this interaction, then the child would likely develop insecurity and/or anxiety, which would affect their ability to form stable relationships with others, develop a sense of self-worth and move towards independence. ${ }^{3}$ Reactions to dental care in children, especially those aged 3-5 years, is usually perceived as children's viewing them as punishment; so there is a sense of shame and fear that causes aggressive reaction, anger, rebellion on the part of children and some of them even refused treatment and openly cried. ${ }^{4}$

Psychological conditions and development of the children is actually much better understood by their parents; however, parents often do not recognize that they have developed an interactive dynamics with their children. This research was designed to determine the influence of parenting style and family characteristics on children's behavior during dental treatment in children aged 3-5 years.

\section{Material and methods}

This study was an observational analytical research with cross-sectional research design. This research was conducted in Dental Hospital Hasanuddin University from February to August 2013. Sample was determined with purposive sampling method based on specific inclusion and exclusion criteria, such as children who stayed with and were raised by biological parents, children who were given dental health education (DHE) and children who had fillings done, endodontics, topical application of fluorite, pit and fissure sealant. Children who had had bad dental experience or dental phobia were not recommended in this research.

To obtain data in the field Parenting Style and Dimension Questionnaire (PSDQ) and frankl behavior rating scale translated into Indonesian language were administered to 130 respondents. This assessment instrument consists of 32 items of 
different statements that can be filled by the father or the mother at the waiting room. Each item was assessed using a likert-type scale; scale anchor 4 shows that parents "Always do" and 1 shows that parents "never do."

During dental treatment, children's cooperation levels were measured with frankl behavior rating scale. This scale divided child's behavior towards dental treatment into four categories, ranging from the obviously positive to obviously negative. A cooperative child showed positive behavior and was scored obviously positive, whereas the uncooperative child showed negative behavior and was scored obviously negative.

Data processing was performed using SPSS version 16.0 and data were analyzed using logistic regression test with a significance level of $p<0.05$.

\section{Results}

The number of children who did exhibit cooperative behavior towards their authoritarian parents as presented in table 1 is $21(38.2 \%)$, while the number of children who were not cooperative to

Table 1 Distribution of authoritarian parenting style towards cooperative levels in children aged 3-5 years who were treated in Department of Pediatric,Dental Hospital Hasanuddin University, Makassar, 2013

\begin{tabular}{lccc}
\hline \multirow{2}{*}{ Parenting Style } & \multicolumn{2}{c}{ Behavior diagnosis } & \\
\cline { 2 - 3 } & Cooperative & Not cooperative & Total \\
\hline Authoritarian n \% & 21 & 34 & 55 \\
& 38.2 & 61.8 & 100.0 \\
Not authoritarian n \% & 59 & 16 & 75 \\
Total n \% & 78.7 & 21.3 & 100.0 \\
& 80 & 50 & 130 \\
& 61.5 & 38.5 & 100.0 \\
\hline
\end{tabular}

Source: Primary data

Note: $\mathrm{n}=$ Total of sample; $\%=$ percentage of sample

Table 2 Distribution of permissive parenting style towards cooperative levels in children aged 3-5 years who were treated in Department of Pediatric, Dental Hospital Hasanuddin University, Makassar, 2013

\begin{tabular}{lccc}
\hline \multirow{2}{*}{ Parenting Style } & \multicolumn{2}{c}{ Behavior diagnosis } & \\
\cline { 2 - 3 } & Cooperative & Not cooperative & Total \\
\hline Permissive $\mathrm{n} \%$ & 20 & 34 & 54 \\
& 37.0 & 63.0 & 100.0 \\
Not permissive n \% & 60 & 16 & 76 \\
& 78.9 & 21.1 & 100.0 \\
Total n \% & 80 & 50 & 130 \\
& 61.5 & 38.5 & 100.0 \\
\hline
\end{tabular}

Source: Primary data

Note: $\mathrm{n}=$ Total of sample; $\%=$ percentage of sample. authoritarian parents is 34 (61.8\%). Table 2 shows that the number of children who were cooperative to permissive parents is $20(37.0 \%)$, whereas the number of children who were not cooperative to permissive parents is 34 (63.0\%). Table 3 shows that the number of children cooperative to authoritative parents is $64(86.5 \%)$, whereas children who were not cooperative to permissive parents is $10(13.5 \%)$.

Logistic regression test results of the influence of parenting style towards children's cooperative levels are presented in table 4 . Each parenting style had a significance value $<p(0.05)$, which means there was a significant amount of influence of each parenting style over children's cooperation levels. Moreover, this table also shows the influence of parenting style towards children's cooperative levels are based on exponent $B$ value. Authoritative parents have the highest amount of influence on the cooperation levels of children aged 3-5 years.

\section{Discussion}

Results in this study show that each parenting style (authoritarian, permissive, and authoritative) have significant influence over the cooperation levels of children aged 3-5 years. This parenting styles were compared to analyze which one of them has the highest influence over the cooperation levels of children aged 3-5 years. The highest level of cooperation in children aged 3-5 years was secured by authoritative parents. This result is in line with Sharma and Sandhu, who stated that parenting style such as warmth, close regulation, strict enforcement of family rules with clear emphasis on consequences of behaviors, and democratic recognition of child's viewpoint have been consistently associated with low levels of behavioral problems. ${ }^{3}$

Stansbury et al. also reported that a permissive parenting style is associated with the development of child's ability to control and direct behavior independently and to cooperate with others because permissive parents give freedom to the child to think and decide on their own about how to act in specific situations. ${ }^{5}$ Existing literature from Afriani et al. documented that authoritative parenting style is significantly associated with positive developmental outcomes among children. This parenting style has been linked to children's social responsibility as well. ${ }^{6}$ Children's behavior would be easy to control during dental treatment if their parents demonstrated an authoritative parenting style.

The influence of permissive parenting style over children's cooperation levels also has been proven to be effective in some studies. In our study, children's cooperation levels had the lowest value if their parents were permissive. From the 
Table 3 Distribution of permissive parenting style towards cooperative levels in children aged 3-5 years who were treated in Department of Pediatric, Dental Hospital Hasanuddin University, Makassar, 2013

\begin{tabular}{lccc}
\hline Parenting Style & \multicolumn{2}{c}{ Behavior diagnosis } & \\
\cline { 2 - 3 } & Cooperative & Not cooperative & Total \\
\hline Authoritative $\mathrm{n} \%$ & 64 & 10 & 74 \\
& 86.5 & 13.5 & 100.0 \\
Not authoritative $\mathrm{n} \%$ & 16 & 40 & 56 \\
& 28.6 & 71.4 & 100.0 \\
Total n \% & 80 & 50 & 130 \\
& 61.5 & 38.5 & 100.0 \\
\hline
\end{tabular}

Source: Primary data

Note: $\mathrm{n}=$ Total of sample; $\%=$ Percentage of sample

Table 4 The influence of parenting style towards cooperative levels in children aged 3-5 years who were treated in Department of Pediatric, Dental Hospital Hasanuddin University Makassar 2013

\begin{tabular}{lcc}
\hline Parenting Style & Sig. & Exp(B) \\
\hline Authoritarian & .047 & .387 \\
Permissive & .037 & .370 \\
Authoritative & .000 & 8.370 \\
\hline *Variblesin the & &
\end{tabular}

${ }^{\star}$ Variables in the equation; $p<0.05$

hypothesis tests, it was concluded that there was a significant amount influence exerted by permissive parenting style over the cooperation levels of children aged 3-5 years. This means permissive parents have the highest potential to make children uncooperative in dental treatment.

This result is supported by Welbury and Duggal, who reported that children raised in permissive homes tend to exhibit non assertive behavior, dependency on parents, and poor self-control. ${ }^{7}$ Onder and Gulay stated that children raised by permissive parents can be selfish. These children do not show interest or empathy towards the feelings and thoughts of others. They may have insufficient self-control, lower self-confidence, and insufficient social skills. ${ }^{8}$

Further analyses in our study found a strong association between the characteristics of children of permissive parents and their behavior during dental treatment. Children with these characteristics have the most potential to cause trouble during dental treatment. In a survey by Soxman et al, it was found that almost 9 out of 10 concluded that they are observing negative changes in parenting styles, and these changes have adversely influenced the behavior of their pediatric patients. Respondents ranked the reasons for this change from highest to lowest; parents are less willing to set limits, less willing to use physical discipline, unsure of their roles as parents, too busy to spend time with their children and were too self-absorbed or materialistic. The consequence is that behavior management techniques have become less assertive. ${ }^{9}$

Based on our research, we found that authoritarian parenting style significantly influences cooperation levels in children aged 3-5 years. Furthermore, influence of authoritarian parenting style over the cooperation levels of children aged 3-5 years had the lowest value compared with other parenting styles. This result is in line with Wendy's research, which found that harsh parenting was the primary determinant of behavior problems for both children aged 2-3 years and 8-9 years. A one-point increase on a 10-point scale of harsh parenting was related to a $50 \%$ increase in the risk for behavior problems.

A research from Sarheed reported that frequently parental expectations for the child's behavior (e.g., no tears) are unrealistic, while expectations for the dentist who guides their behavior are great. Some parents may even try to dictate treatment, although their understanding of the procedure is lacking. These conditions would indirectly make the job of the dentist more difficult in controlling the child's behavior during treatment. ${ }^{10}$ In addition, Boynes et al. reported that pediatric anxiety and fear of dental care are multifactorial and the parents have a significant role in their development. ${ }^{11}$ The communication process between the child and the patient may have negative connotations, which may cause children to refuse to be cooperative during dental treatment. Effective communication with more challenging parents represents a chance for the dentist to go cautiously over the child's behavior and treatment options and, with cooperation and inputs from the child's parents, decide the course of action that is in the best interest of the child. ${ }^{11,12}$

\section{Conclusion}

From this study, it can be concluded that there is a significant amount of influence of parenting style over the cooperation levels in children aged 3-5 years during dental treatment. The authoritative parenting style has the maximum influence on the cooperation levels of children aged 3-5 years during dental treatment. For further research, we suggest to analyze the influence of parenting style in school-aged children using a different assessment scale.

\section{Conflict of Interest}

The authors report no conflict of interest. 


\section{References}

1. Lara A, Crego A, Maroto MR. Emotional contagion of dental fear to children: the fathers' mediating role in parental transfer of fear. Int J Paediatr Dent 2012;22: 324-325.

2. Suprabha BS, Rao A, Choudhary S, et al. Child dental fear and behaviour: the role of environmental factors in hospital cohort. I Indian Soc Pedod Prev Dent 2011;29: 95-96.

3. Sharma V, Sandhu GK. A community study of association between sparenting dimensions and externalizing behaviors. J Indian Assoc. Child Adolescnt Health 2006;2: 48-49.

4. Hoang TN. The relations between parenting and adolescent motivation. Int. J. Web Science 2007;13: 1-8.

5. Stansbury K, Haley D, Holly E, et al. Adult caregivers' behavioral responses to child noncompliance in public settings: gender differences and the role of positive and negative touch. Behav Soc Issues 2012;21: 80-2, 91-92.

6. Afriani A, Baharudin R, Nor S, et al. The relationship between parenting style and social responsibility of adolescents in Banda Aceh, Indonesia. J. Soc Sci and Hum 2012;20: 736-737.

7. Welbury R, Duggal M. Pediatric Dentistry 3rd ed. United States: Oxford University Press; 2005. p. 9-17.

8. Onder A, Gulay H. Reliability and validity of parenting styles \& dimensions questionnaire. Procedia Soc and Behav Sci 2009; 508-509.
9. Soxman J, Park A, Pennsylvania. Parenting the parents of pediatric patients. Comp Cont Educ Dent 2006;27: 631-633.

10. Sarheed MA. Children's perception of their dentists. Eur J Dent 2012;5: 187-190.

11. Boynes SG, Abdulwahab M, Kershner E, et al. Analysis of parental factors and parent-child communication with pediatric patients referred for nitrous oxide administration in a rural community health center setting. Oral Bio and Dent 2014;2: 1-8.

12. Singh H, Rehman R, Kadtane $\mathrm{S}$, et al. Techniques for the behaviors management in pediatric dentistry. Int J Sci Stud 2014;2: 269-272.

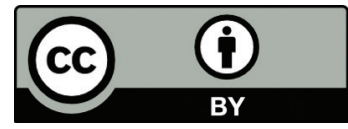

This work is licensed under a Creative Commons Attribution 